Savunma Bilimleri Dergisi

The Journal of Defense Sciences

Mayıs/May 2019, Cilt/Volume 18, Sayı/Issue 1.

ISSN (Bas1l1) : 1303-6831 ISSN (Online): 2148-1776

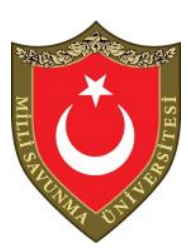

\title{
Havalı Silah Sistemleri İçin Tek Parçalı Susturucu Tasarımı *
}

\author{
Mustafa BOZDEMIR**
}

$\ddot{O} z$

Merminin ateşlenmesi sırasında oluşan sesler, ateşleme sonrası hava türbülansı ve mermi burnu tarafindan üretilen süpersonik şok dalgası veya balistik çatlağın neden olduğu dalgalanmadır. Bu çalışmada, havalı silahlar için tek parçalı susturucunun bilgisayar destekli tasarımı yapılmıştır. Bu susturucunun üç boyutlu yazıcı yardımiyla basılmasi sirasinda, uygulanmasi gereken tasarım ve imalat süreçleri belirlenmiştir. Havalı silah susturucu tasarımı üzerinde üç boyutlu yazıcı bask parametreleri incelenerek, susturucu imalatında üç boyutlu yazıcıların uygunluğu tartışılmıştır. Tek parça halinde imal edilebilme imkânı sağlayan $3 B$ yazıcı teknolojisi sayesinde, ucuz, hızlı ve etkili havalı silah için susturucu imalatı yapılabilmiştir.

Anahtar Kelimeler: Susturucu, 3B Yazıcı, Namlu Gürültüsü.

\section{Single Particle Suppressor Design For Airgun Systems}

\begin{abstract}
The projectile noises are mainly those caused by air turbulence following the projectile and the supersonic shock wave or ballistic crack generated by the projectile nose. In this study, computer aided design of the single particle suppressor for air guns. The design and fabrication processes that need to be applied during the manufacture of this masonry $3 D$ printer are described. By examining the $3 D$ printer printing parameters on suppressor for air guns, the suitability of $3 D$ printers in suppressor manufacturing is examined. $3 D$ printer
\end{abstract}

\footnotetext{
* Bu çalışma $3^{\text {rd }}$ International Congress on 3D Printing Technologies and Digital Industry, 19-21 Nisan 2018 Antalya, Türkiye'de sempozyumda sunulmuştur.

** Prof.Dr., Kırıkkale Üniversitesi, FBE Savunma Teknolojileri Bölümü, mustafabozdemir@kku.edu.tr
}

Geliş Tarihi/Received:06.08.2018

Kabul Tarihi/Accepted:17.11.2018 Araştırma Makalesi/Research Article 
technology allows to be manufactured the objects in one piece. Suppressor production can be easily made such as cheap, fast and effective for air gun.

Keywords: Suppressor, 3D Print, Muzzle Noise.

\section{Giriş}

Barutun keşfiyle birlikte, insanların savunma ve saldırı amaçlı tercih ettikleri silahlarda değişim süreci gözlenmiştir. İlkel saldırı ve savunma araçları olan kılıç, mızrak ve sopaların yerlerini patlama özellikleri taşıyan savaş araçları almıştır. Teknolojik gelişmelere paralel olarak barut teknolojisi ve silahları da hızla gelişerek, günümüz ateşli silah teknolojilerine kadar gelmiştir. Barutun sevk elemanı olarak kullanımı, günümüzde hâlâ vazgeçilmez bir özelliktir.

Ateşli silahların ilk ortaya çıkışından bu yana hemen her dönemde çok mermi atan toplardan, cep tabancalarına kadar çeşitli silahlar yapılmıştır. Ancak bu tip silahlarda, ateşleme mekanizmasının şekli ve etkili bir gaz kaçağı önleme sistemi olması silah performansına önemli etki sağlamıştır. 16. yüzyılda birden fazla namlulu, döner namlulu ya da tek namlusu içine birden fazla mermi konup tek ya da birkaç mekanizma ile ateşlenen çeşitli tipte silahlar ortaya çıkmıştır. Ama bunlardan sadece çok namlulu silahlar ve özellikle tabancalar başarılı olmuştur. Arka arkaya seri atış yapabilen tüfekler 1880-1890'larda birçok ülkenin silahlı kuvvetleri tarafından benimsenmiştir (Ateşli Silahlar, 2017).

Ateşli silahlar, kimyasal enerjinin kinetik enerjiye dönüştürüldüğü sistemlerdir. Kimyasal enerji kaynağı olarak yanıcı bir madde olan barut kullanılmaktadır. Barut silahın atım yatağında yanmakta ve katı fazdan gaz fazına geçmektedir. Bu gazlar atım yatağı içerisinde sıcaklığın ve basıncın artmasına neden olmaktadır. Basınç, merminin ilk hareketini başlatacak seviyeye geldiğinden itibaren mermi namlu boyunca hızlanarak hareket etmektedir (Gezer, 2017) .

Ateşli silahlarda itici güç kaynağı olarak günümüzde Nitroselüloz ve Nitrogliserinin değişik oranlarda karışımından oluşan "dumansız barut" tur. Barut ateşlendiğinde, ilk hacmine kıyasla 1300 kata kadar genişleyen bir gaz hacmi oluşur, namlu içindeki sıcaklık birkaç milisaniye süreyle $1000{ }^{\circ} \mathrm{C}$ 'yi aşabilir. $\mathrm{Bu}$ kısa sürede namlu içinde oluşan, yaklaşık 200-300 N/mm² basıncın büyük kısmı kinetik enerjiye dönüşüp mermi çekirdeğini hedefe doğru itmektedir. Enerjinin bir kısmı "geri tepme" etkisi olarak kişiye aktarılırken, bir kısmı da otomatik-yarı 
otomatik silahlarda silahın bir sonraki atış için kurulması ve namluya yeni bir mermi sürülmesinde harcanır (Yılmaz, 2004).

Ateşli silahlarda merminin namludan istenilen hızla firlatılabilmesi için, sevk yakıtı olarak barut kullanılır. Ateşlenen barutun yanmasıyla oluşan itici gazlar ve oluşan yüksek basınç namlu içinde mermiye istenilen hareketi sağlamaktadır. Namlu içerisinde barutun yanması sonrasında yüksek basınç, silah namlusundan merminin çıkışıyla birlikte gürültü oluşmasına sebep olur. $\mathrm{Bu}$ gürültü ateşli silahlarda istenmeyen bir etkidir. Bazı özel durumlarda ve ortamlarda bu ateşli silah sesini azaltmak amacıyla özel tasarım sistemlere ihtiyaç duyulmaktadır. Silah namlusu önüne takılan susturucular amacı, merminin ateşleme gürültüsünü azaltmaktır. Ateşli silah susturucusu, silah namlu boy ve çapının oluşturduğu hacmin 20-30 katı daha büyük hacme sahiptir. Bu sayede namludan çıkan basınçlı gaz susturucu içerisindeki bölmelerde tutularak ani basınç çıkışı engellenir. Silah namlu önünden geriye kalan düşük miktarda basınç ise etrafı rahatsız etmeyecek oranda bir ses çıkışına neden olabilir. Silah sistemleri ve susturucu gibi yardımcı silah yapıları tasarlanırken iç balistik hesaplamalar büyük önem taşımaktadır. Başta silahın fonksiyonunu yerine getiren parçaların mukavemet hesaplamaları olmak üzere ve diğer yardımcı mekanizmaların üzerinde de basınç, sıcaklık ve tepki kuvvetleri gibi etkiler oluşturduğu göz önünde bulundurulmalıdır.

Literatürde ateşli silahlara ait çok fazla çalışmaya rastlanırken, havalı silah sistemlerine ait çalışmanın sayısının az olduğu görülmüştür. Bunun ana sebeplerinden birisinin, bu tip silahların spor ve avcılık gibi alanlarda daha çok kullanılmasından kaynaklı olduğu düşünülmektedir. Havalı silahların da ateşli silahlar kadar öldürücü ve zarar verici etkileri bulunmaktadır. Spor amaçlı kapalı alanlarda yapılan atışlarda ve eğitim amaçlı kullanım sırasında ortaya çıkan basınçlı hava sesi çevresindeki canlılara rahatsızlık vererek, çeşitli sağlık sorunları oluşturabilmektedir. Bu nedenle bu tip silahlara yönelik olarak susturucu ve silah yardımcı hedefleme sistemleri geliştirilmektedir. Bu çalışmada, havalı silah sistemleri için geliştirilen tek parçalı bir özel susturucu tasarımı yapılmıştır. $\mathrm{Bu}$ tasarımın 3B yazıcıyla prototip imalatı yapıldıktan sonra, test süreçleri belirlenmiş ve uygulanmıştır. 


\section{Silah Sistemleri}

Ateşli, ateşsiz, kimyasal, biyolojik ve nükleer silahların tümü, genel anlamda silah kelimesinin kapsamını oluşturmaktadır. Silah; "uzaktan ya da yakından canlıları öldürebilen, yaralayan, etkisiz bırakan, canlı organizmaları hasta eden, cansızları parçalayan, yok eden araç ve aletlerin tümüne" denir. Mermiye, ateşlenen barut gazıyla itici güç vererek hedefe ulaştırmaya yarayan aletlere ateşli silah denir (Gündüzer, 2011).

\section{a. Ateşli Silahlar}

Tabanca, tüfek gibi silahlar ateşli silah grubunda gösterilen silah tipidir. Tabancanın aksine uzun namlulu hafif silahlar genellikle omza dayalı olarak atış yapılan silahlardır. Uzun namlulu silahlar savaş tüfekleri ve av tüfekleri gibi iki bölüme ayrılır. Savaş tüfekleri yiv ve setli olup, uzun menzil ve tahrip gücü yüksek olan silahlardır. Ateşli silahların en önemli parçası mermidir. Ağır ve hafif silah mermileri arasında yapısal farklılıklar bulunur. Hafif silah mermilerine fişsek denilir ve dört temel bölümden oluşur. Fişeğin namludan hızla çıkan, uç bölümü mermi çekirdeğidir. Silah ateşlendiğinde, içeride oluşan yüksek gaz basıncı mermi çekirdeğini hedefe doğru firlatır. İkinci bölüm olan sevk barutu, yanma sonrası istenilen basınç artışını sağlamaktadır. Üçüncü bölüm mermi kovanıdır. Mermi kovanı, fişek parçalarının hepsini bir arada tutan ve gövde görevi yaparak barutun doldurulduğu kısımdır. Son olarak kovanın arkasında, barutun yakılmasını sağlayan kapsül bölümü yer alır. Kapsül fişeğin ateşlenmesi sağlar ve tetik mekanizmasıyla tahrik edilir. Şekil 1'de bir hafif silah sisteminin iç yapısı ve temel bazı bileşenleri görülmektedir. 


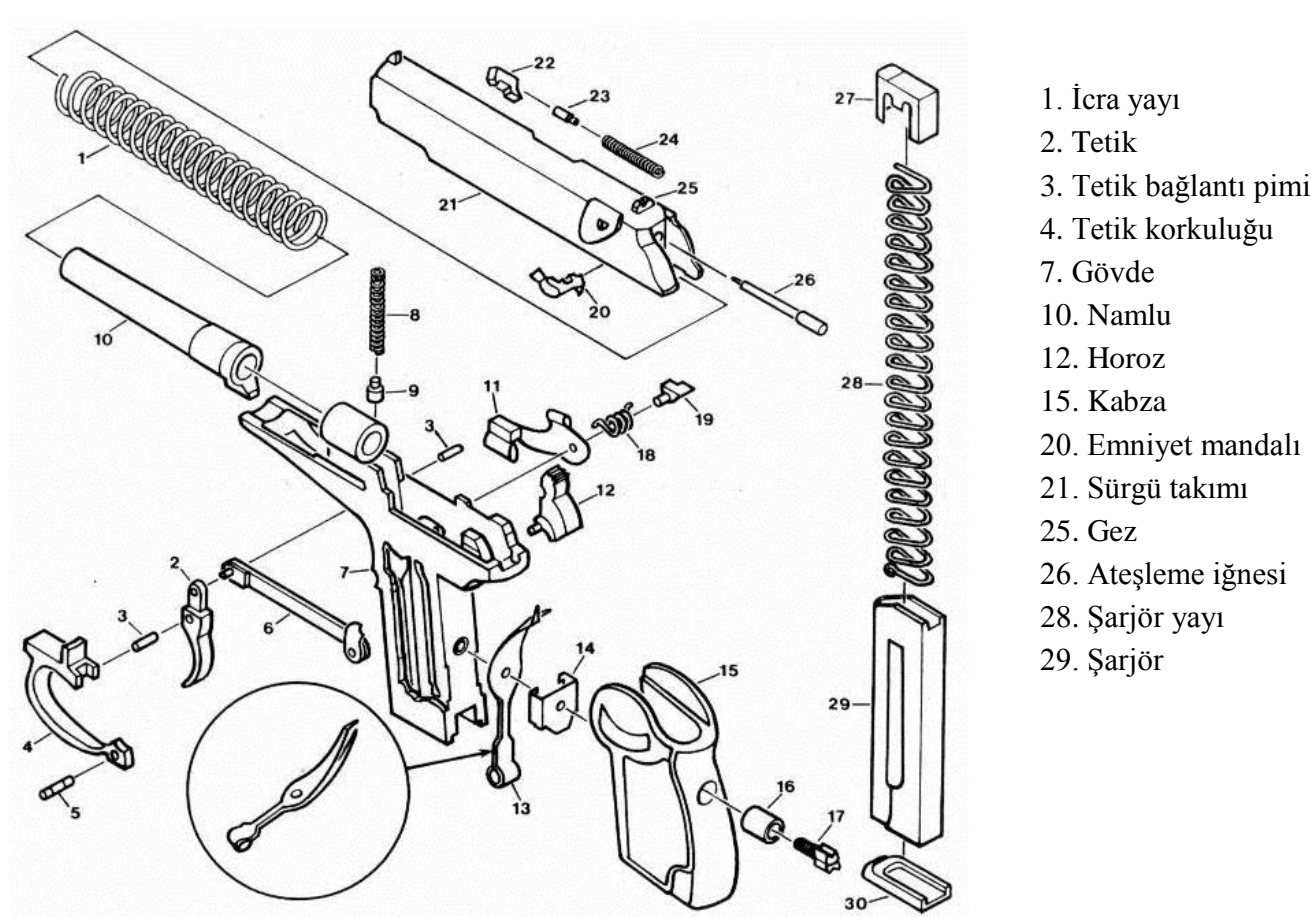

Şekil 1. Ateşli hafif silahın yapısı (Technical information, 2018)

Silah ateşleme iğnesinin çarpmasıyla fişek kapsülü patlar ve kovandaki barutu tutuşturur. Barutun yanmasıyla ortaya çıkan sıcak gazın basıncı, mermi çekirdeğini ileriye doğru iterek ve çekirdek namlu ağzından hızla hedefe doğru fırlatır. Bu sırada, ağır ateşli silah namluları içinde basınç yaklaşık $410 \mathrm{~N} / \mathrm{mm}^{2}$ 'ye kadar yükselir. Barutun yanması sonras $2800{ }^{\circ} \mathrm{C}$ 'yi aşan büyük bir sıcaklık ve 1300 kata kadar genleşen gaz basıncı meydana gelir. Çok kısa sürede oluşan ve 200-300 N/mm², ye ulaşan basıncın büyük bir kısmı mermiyi namluya iterek hareket ettirir. Mermi namlu içerisinde setlere sürtünerek ve aynı zamanda dönü etkisini de kazarak namlu boyunca hızlanarak ilerlemektedir. Barutun yanmasıyla ortaya çıkan enerjinin bir kısmı geri tepme kuvvetinin oluşmasına, diğer kısmı ise silahın yeni atışı için mekanizmasın kurulmasında yay-silindiri sıkıştırmaktadır (Farrar and Leeming, 1983). 


\section{b. Havalı Silahlar}

Havalı silahlar, hava veya gazın sıkıştırılmasıyla sağlanan basıncın itme kuvveti olarak kullanılması ve özel şekilli mermi tanelerini atan silahlardır. Havalı silah tekniğiyle çalışan tüfek ve tabanca sistemleri günümüzde yaygınlaşmaktadır (Warlow, 1996). Havalı silah sistemlerini amaçlarına ve özelliklerine göre, nişan ve av silahları olarak ikiye ayırmak mümkündür (Air rifle, 2018).

Havalı nişan silahları; $10 \mathrm{~m}$ ileride bulunan hedefte $4,5 \mathrm{~mm}$ çapında $(0,177$ Kalibre) mermiyle istenilen isabetin sağlanması için gereken kinetik enerjiyi üreten silahlardır (Straight Shooters Precision Airguns, 2018). Havalı silahlar; yayl1-pistonlu-silahlar, pnömatik silahlar ve $\mathrm{CO}_{2}$ tüp havalı silahlar olarak gruplandırılır (Warlow, 1996)

Yaylı Pistonlu Havalı Silahlar; yay baskısı altında bulunan piston veya pistonlar tarafından sıkıştırılan havanın itme kuvvetinden faydalanarak merminin namludan dışarıya atılmasını sağlayan havalı silah sistemleridir (Airguns, Accessories, 2018).

Pnömatik havalı silahlarda pistonun bağlı olduğu manivela sistemi yardımıyla, pistonun arka tarafındaki hazne içerisine hava alma imkânı veren boşlukları açar ve hazneye hava emer. Manivelanın tekrardan kapatılmasıyla piston ileriye doğru hareketle haznedeki havayı sıkıştırır. Yaklaşık $200 \mathrm{Bar}$ basinca sahip bir tüple arka arkaya ortalama $300-350 \mathrm{~m} / \mathrm{s}$ ilk hizlara sahip en az 100 atış yapabilmektedir (How works air rifles, 2019). Şekil 2'de bir $\mathrm{CO}_{2}$ tüplü silahın içyapısı ve çalışma sistemi görülmektedir. 


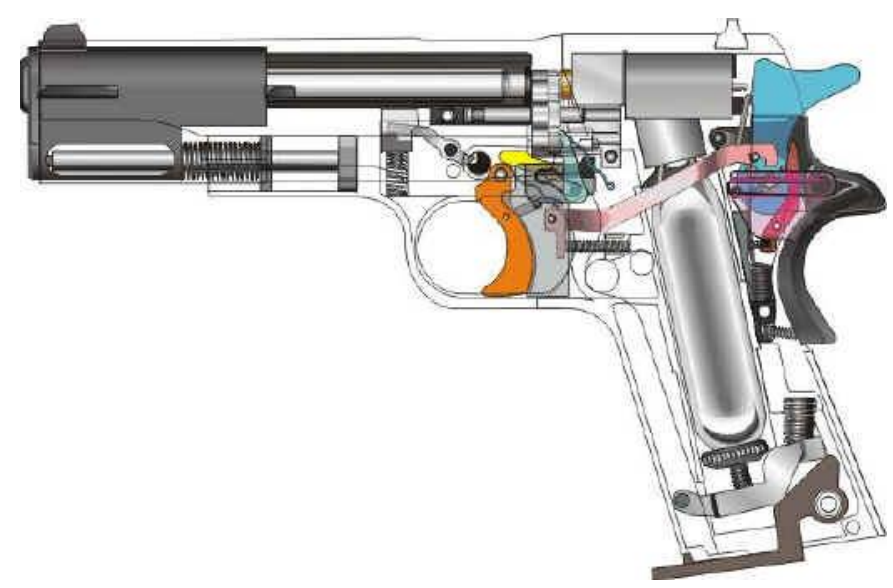

Şekil 2. $\mathrm{CO}_{2}$ tüplü silahın iç yapısı (Cold, 2018)

Karbondioksit tüplü silahlarda, 12-18 g ağırlığındaki $\mathrm{CO}_{2}$ dolu metal tüpler gövde içerisine yerleştirilmektedir. Gaz tüpleri kısa namlulu silahlarda kabza içerisindeki boşluğa, uzun namlulu silahlarda dipçiğin içerisinde uygun görülen bir pozisyona konumlandırılmaktadır. Karbondioksit gaz tüpü kullanan havalı silahların diğer havalı silahlara göre en önemli avantajı, tüpü taktıktan sonra silahın atışa hemen hazır olmasıdır. Bir gaz tüpü ile ortalama olarak 50 atış yapılabilmektedir. Bir diğer avantajları da düşük üretim maliyetleridir.

\section{c. Susturucu}

Susturucular, silah namlusuna takılan ve ateşleme esnasında ortaya çıkan yüksek şiddetli ses dalgalarını azaltmaya yarayan bir genleşme odası ve ilave odacıklardan oluşan bir yapıda imal edilmektedir. Silah susturucuları silahı kullanan keskin nişancıların yerinin tespitini güçleştirdiği gibi kalabalık yerlerde ya da meskenlerde fark ettirmeden silahın ateşlenmesini sağlar (Seçgin ve Arslan, 2012).

Şekil 3'te bir silah namlusuna montaj edilmiş, susturucu ve kesiti görülmektedir. Namlu ağzından çıkan yüksek basınçlı itici gazlar, susturucu içinde oluşturulmuş odacıklara hapsedilerek, namlu ağzı basıncı sadece 4 Bar'a kadar düşürülebilir. Basınç düşmesi sonrasında ateşli silahlarda duyulan patlama sesi de azalmaktadır. 


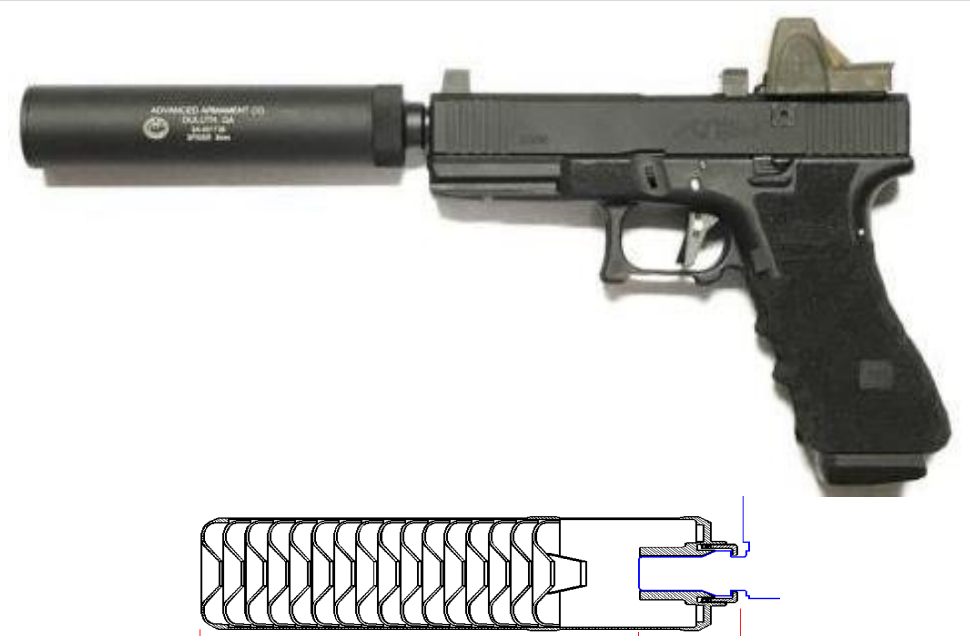

Şekil 3. Susturucunun montajı ve kesit görünüşü (Silencers, 2018).

Verilmiş bir ses şiddeti değerinin kendisinden 10 kat az diğer bir ses şiddet değerine oranının 10 tabanına göre logaritmasına eşit ses şiddeti değerine bel, bunun 1/10'una da desibel denir. Gürültü desibel $(\mathrm{dB})$ ile ölçülür. Desibel, ölçümü yapılan ses basıncının referans basınca oranın logaritmasıdır. Eşitlikle ifade edilmek istenirse; ses şiddeti seviyesi $(\mathrm{dB})$, aşağıdaki eşitlikle hesaplanabilir.

$$
L p=10 \log \left[\frac{P}{P_{0}}\right]^{2}
$$

Burada; P: Ses basinc1 $\left(\mathrm{N} / \mathrm{m}^{2}\right)$ ve $\mathrm{P}_{0}$ : Referans ses basinc1 $\left(2 \times 10^{-4} \mathrm{~N} / \mathrm{m}^{2}\right)$ değeri olarak alınmaktadır.

Ateşli silahlarda susturucu kullanımı silah gürültüsünün azaltmasında oldukça etkili olurken, aynı zamanda merminin namlu çıkış hızını da azalttığı bilinmektedir (Menzies, Scroggie and Labowitz, 1981).

Gürültü; istenmeyen, rahatsız edici ya da sağlığı tehdit eden seslerdir. Gürültünün etkisine karşı insan davranışları iki grupta toplanmaktadır. Birincisi, duyuların açılanmasıyla belirlenebilen psikolojik rahatsızlıktır. Diğeri ise; ancak çeşitli ölçme metotlarıyla belirlenen fizyolojik rahatsızlıktır. Gürültünün canlılar üzerindeki bazı dikkat çekici etkileri arasında, psikolojik bozukluklar, iletişimi engelleme ve kalıcı duyma bozukluğu riski en önemli etkenler olarak göz önüne alınmaktadır (ÇOB, 2011).

Susturucu tasarımı sırasında ana amaç, namludan çıkan yüksek itici gaz basıncını, namlu çıkışında tutarak, mümkün olan en düşük seviyelere getirmektir. 
Bölmenin yerleştirilme açısı, hacmi, basınç giriş delikleri ve yapısı, susturucunun performansını etkilemektedir. Tasarlanan susturucunun başarısı, takıldığı silahın teknik özellikleriyle de uyumlu olmasıyla yakından ilgilidir. Silahın namlu çapı, mühimmat türü, kullanılan barut miktarı, cinsi, namlu boyu, yiv-set sayısı ve açısı gibi değerlerin susturucu performansı üzerinde etkisi vardır. Susturucular tek parçalı ve çok parçalı iç yapıda imal edilebilmektedirler.

\section{Materyal ve Yöntem}

$\mathrm{Bu}$ çalışma kapsamında, havalı silah sistemine uyumlu, 3B yazıcıda tek parçalı imal edilebilir ve üç ara bölme duvarlı yapıda bir susturucunun CAD programında farklı hacimli tasarımları çizilmiştir. Tasarlanan bu özel susturucuların 3B yazıcı için gerekli baskı parametre ayarlamaları yapılarak, prototip imalatları elde edilmiştir. Prototip susturucuların test ortamında havalı silaha takılarak atış denemeleri yapılmıştır. Atışlar sonrasında, silah namlu ucu ses çıkış değerleri ölçülerek imal edilen prototip susturucu modellerinin ses azaltma yetenekleri belirlenmiştir.

\section{a. Bilgisayar Destekli Tasarım-İmalat (CAD-CAM)}

Bilgisayar destekli tasarım veya kısaltma haliyle CAD terimi, mühendislik tasarımcılarının tasarımlarını geliştirmek, değiştirmek ve son şekle sokmak için bilgisayardan yararlandıkları bir işlemi tanımlar.

$\mathrm{Bu}$ çalışmada, tasarım işleminin gerçekleştirilmesinde SolidWorks programının modelleme ortamından faydalanılmıştır. Silah susturucu sistemine ait 3B modeller hazırlandıktan sonra dosya dönüşümüyle katmanlı model haline getirilmektedir. CAD yazılımlarıla hızlı prototipleme makineleri arasında veri transferini sağlamak için STL (Stereo Lithography) formatına ihtiyaç duyulmaktadır. Üç boyutlu tasarım programları aracıllı̆ııla istenilen susturucu tasarımı yapıldıktan sonra *.stl formatına dönüştürülmektedir. Şekil 4'de SolidWorks ortamında modellenmiş, özel amaçlı tek parça ABS malzemeden üretilmiş havalı silah susturucu sistemine ait 2 ve 3 boyutlu çizimler görülmektedir. Geliştirilen tek parçalı susturucu modeli havalı silah sisteminde kullanılmak üzere imal edilmiştir. Yüksek namlu sıcaklığı olmayacağı için, metal yerine dayanımı yüksek mühendislik plastiği olan ABS malzeme kullanılmıştır. 3B yazıcı 
teknolojisiyle ABS malzeme kullanılarak tek parça halinde dayanımlı susturucu prototipi imal edebilmek bu sayede mümkün olmaktadır.

Kullanılan ABS malzemeye ait mühendislik değerleri Tablo 1'de gösterilmiştir. Ateşli silah teknolojilerinde kullanılan susturucular, namlu çıkış sıcaklığı yüksek olduğundan dolayı metal alaşımlarından yapılmalıdır. Ateşli silahlarda çok atışlı kullanıma yönelik plastik susturucu yapımı mümkün değildir. $\mathrm{Bu}$ çalışmada, kullanılan silah türü, $\mathrm{CO}_{2}$ tüplü silah olduğu için $\mathrm{ABS}$ plastik kullanımına imkân sağlamaktadır.

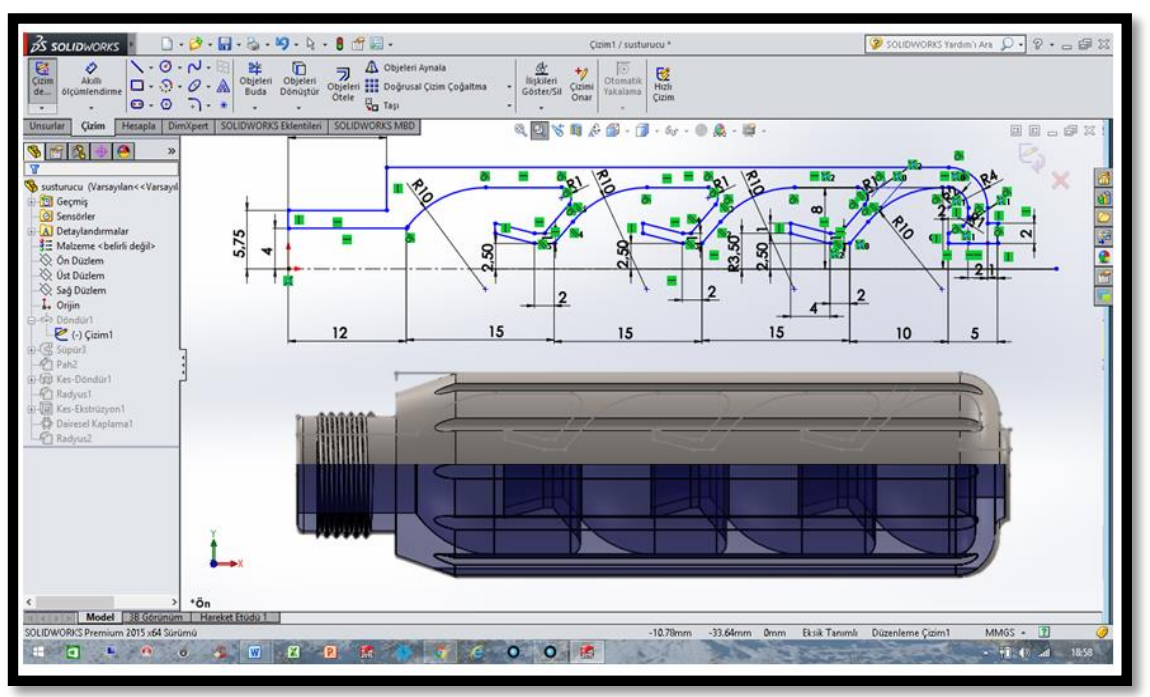

Şekil 4. Geliştirilen tek parçalı susturucu prototipi

\section{b. Prototip İmalatı}

Üç boyutlu havalı silah susturucu modelinin hazırlanmasından sonra, bu modelin STL formatındaki matematiksel hesaplanmış katmanlara dönüşümü yapılmıştır. Şekil 5'de Zortrax 3B yazıcıyla susturucu imalatı ve Z-Suit isimli yazılımla 3B yazıcı baskı ayarları ara yüzü görülmektedir. Program ara yüzü üzerinden, baskı yapılacak malzeme türü, kalınlığı, baskı kalitesi, iç doluluk oranı, destek açısı gibi baskı değişkenleri belirlenebilmektedir. 

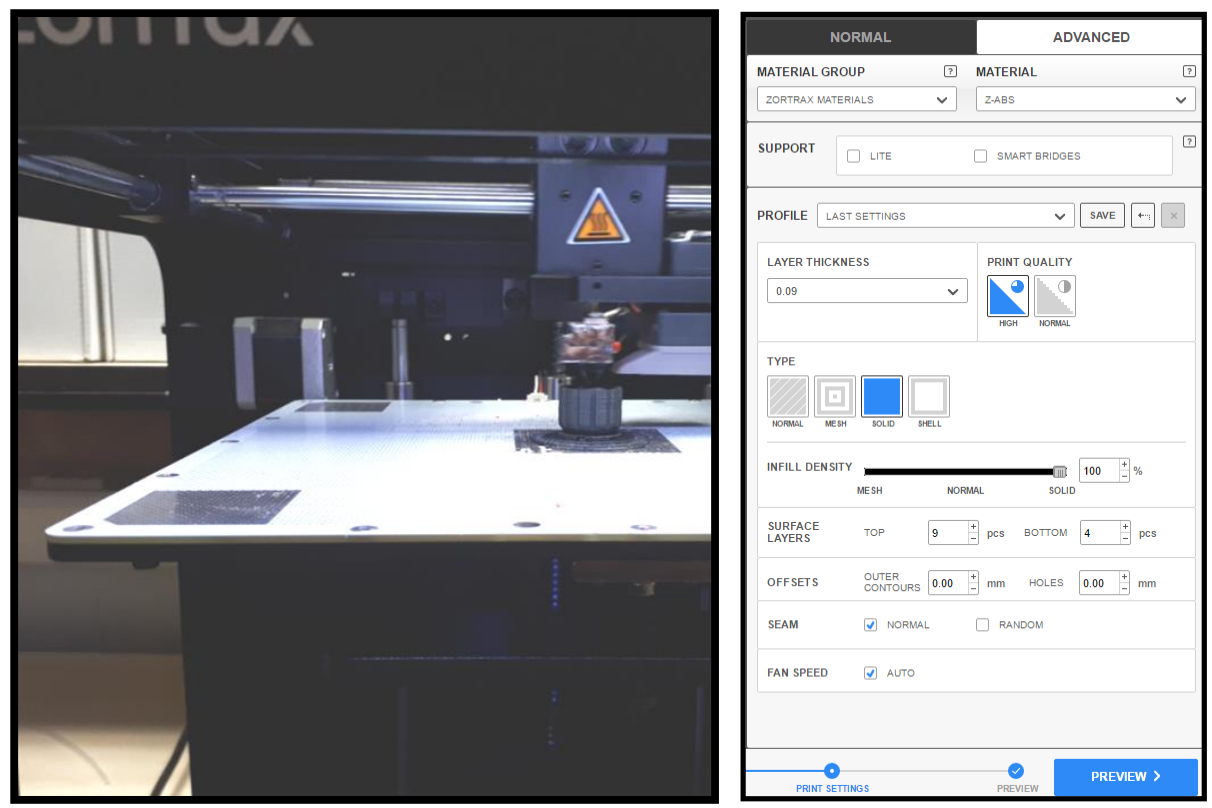

Şekil 5. Zortrax yazıcıyla susturucu baskı anı ve Z-suit 3B baskı ayarları

Havalı silah susturucu imalatında 3B Bask1 cihazı Zortrax M200'dür. M200 modeli 200x200x185 mm üretim hacmi ve 0,09 mm bask1 hassasiyetiyle modellerinin üretimine imkân vermektedir. Yazıcı Ergiterek Yığma Modelleme (FDM - Fused Deposition Modelling) teknolojisini kullanmaktadır. Bu yazıciyla ABS ve PLA gibi termoplastik polimer malzemeler basilabilmektir.

Tek parçalı susturucu prototipinin Zortrax M200 3B yazıcıda imalatı sırasında en hassas baskı kalınlığı olan 90 mikron tercih edilmiştir. Bu kalınlıkta baskı süresi artmış olmasına rağmen, kaliteli bir baskı yüzeyi elde edilmiştir. Kullanılan nozül ucu $0,4 \mathrm{~mm}$ çapındadır. Filament malzeme çapı $1,75 \mathrm{~mm}$ dir. ABS malzeme erime sıcaklığ $1 \sim 220-225^{\circ} \mathrm{C}$ 'dir. Isitmalı tabla kullanılarak malzeme çarpılması azaltılmıştır. Zsuit programında baskı dolgu kalitesi, tamamen dolu malzeme olarak seçilmiştir. İmalat sırasında modelin yapısı ve yerleşim şekli nedeniyle, hiçbir destek parçaya ihtiyaç duyulmadan tek parçalı imalat yapılabilmiştir.

Havalı silah susturucu modelinin prototip çalıșmaları sırasında ZortraxABS malzeme kullanılmıştır. $\mathrm{CO}_{2}$ tüplü silah namlu ucu sıcaklığının ABS malzemenin erime sıcaklığından çok daha düşük olması ve $A B S$ malzeme 
dayanımının yüksek olması nedeniyle, Zortrax-ABS filament malzeme prototip imalatı için uygun görülmüştür. Tablo 1'de Zortrax markası için üretilen filamente ait bazı mühendislik değerleri gösterilmiştir.

Tablo 1. Kullanılan ABS filamentin mühendislik özellikleri (3D printer, 2018)

\begin{tabular}{|c|c|c|}
\hline ÖZELLIKLER & TEST METODU & DEĞRĖ \\
\hline Elastisite Modülü & ISO 527-2 & $1,80 \mathrm{GPa}$ \\
\hline Çekme Dayanımı & ISO 527-2 & $38 \mathrm{MPa}$ \\
\hline Darbe Dayanımı & ISO $179-1$ & $8 \mathrm{~kJ} / \mathrm{m}^{2}$ \\
\hline Sertlik & ISO $2039-1$ & $109(\mathrm{Rockwell})$ \\
\hline Erime Sıcaklı̆̆ı & - & $250-260 \mathrm{C}^{0}$ \\
\hline Yumuşama Sıcaklığı & - & $112 \mathrm{C}^{0}$ \\
\hline
\end{tabular}

\section{c. Deney Düzeneği ve Ölçümler}

Havalı silah susturucu prototipi atış testleri ve gürültü ölçümleri Kırıkkale Üniversitesi 3B Tasarım ve Prototipleme laboratuarındaki güvenli bir alanda yapılmıştır. Havalı silah susturucu prototipleri CZ75P-07 modelinin $\mathrm{CO}_{2}$ hava tüpü ile çalışan tipine montajlanmıştır. Silahın özellikleri, kalibre çapı $4,5 \mathrm{~mm}(0,177)$ $\mathrm{BB}$, ürettiği atış hızı $104 \mathrm{~m} / \mathrm{s}$ (341 fps) ve güç kaynağı tipi 12 gr $\mathrm{CO}_{2}$ hava tüplü şeklindedir. Tam metal gövde ve yarı otomatik mekanizmaya sahip olup, şarjör kapasitesi 20 atışlık mermi bulundurmaktadır. El emniyet mekanizmasına sahip olan bu silahta namlu ucunda susturucu bağlantı vidası vardır. Namlu uzunluğu $83,5 \mathrm{~mm}$ ve silah ağırlığı 820 g'dır. CZ75P-07 havalı silahla susturuculu ve susturucusuz atışlar yapılarak gürültü ölçümleri alınmıştır. CZ75P-07 test silahına ait görüntü Şekil 6'da verilmiştir. 


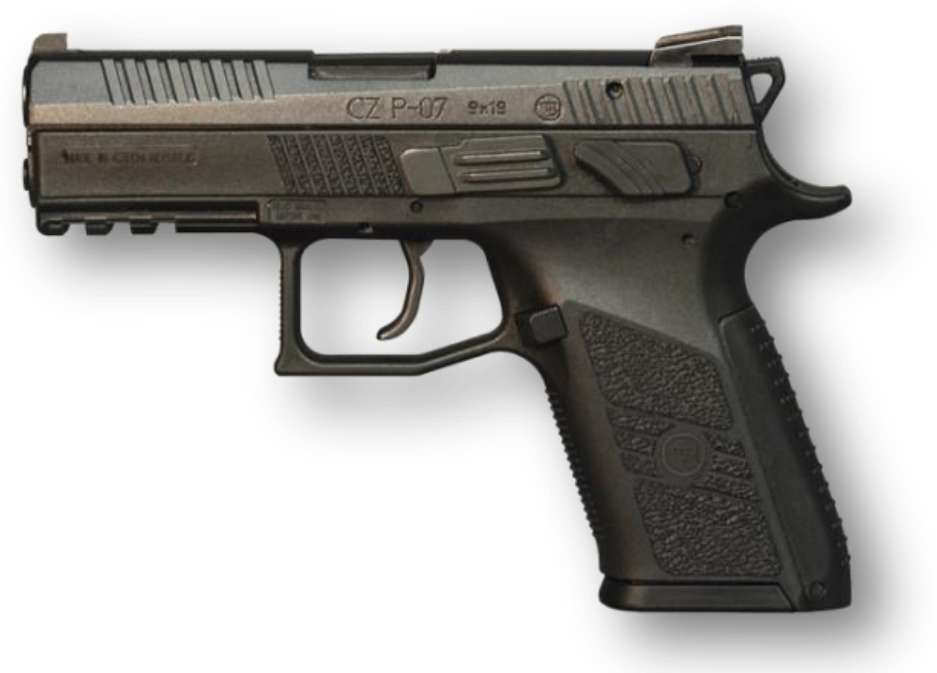

Şekil 6. Prototip susturucunun bağlandı̆̆ test silahı

Atış ortamı ve deney düzeneği Şekil 7'de görülmektedir. 3B yazıcıda iki farklı modelde hazırlanan susturucularla yapılan test atışları ve ortalama değerleri elde edilmiştir. Birinci prototip modeli $\varnothing 20 \times 72 \mathrm{~mm}$, ikinci prototip modeli ise $\varnothing 34 \times 94$ mm ölçülerinde imal edilmiştir. Atışlar sırasında ses ölçüm aleti ve silahın konumu aynı olacak düzenek oluşturulmuştur. Silah atış masasına sabitlenerek hareket etmesi engellenmiştir. Ses seviyesi ölçüm aleti sürekli aynı konumda bulundurularak, ölçümlerin birbiriyle olan doğruluğu sağlanmıştır. 


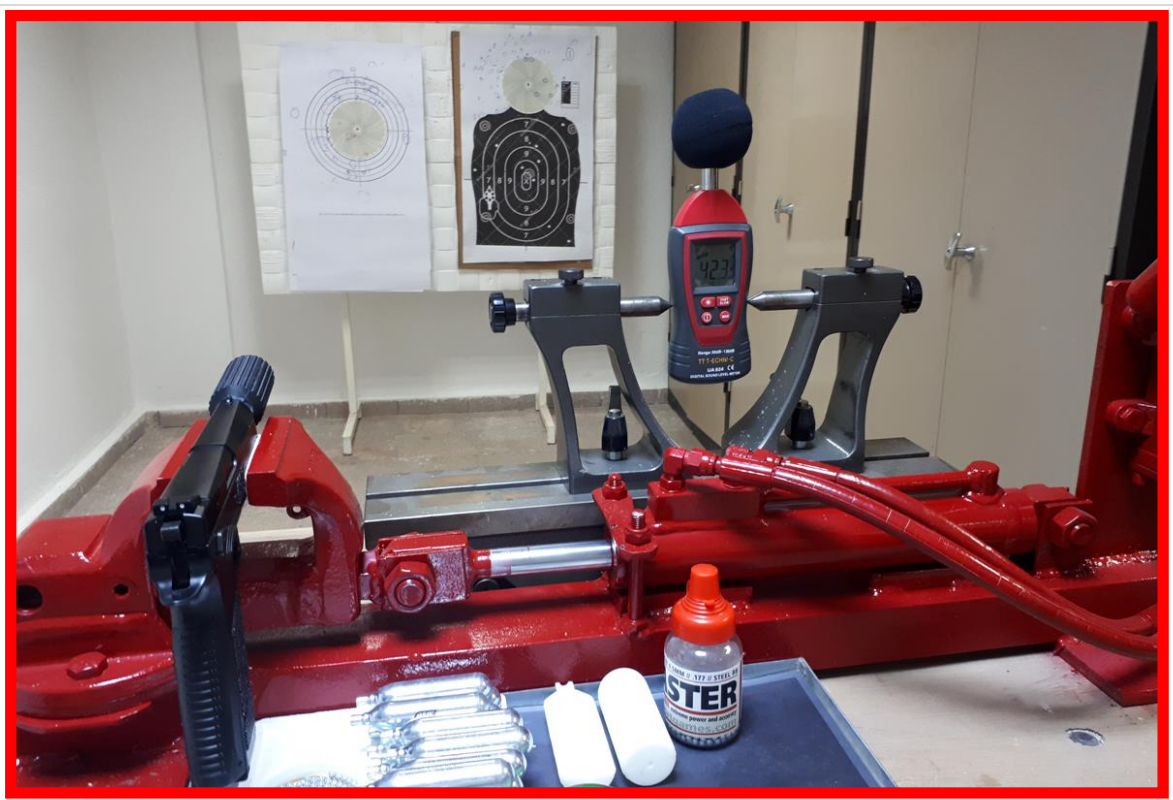

Şekil 7. Atış test ve ses seviyesi ölçüm düzeneği

Atış testlerinde gürültü seviyesinin ölçümünde TT Technic UA824 ses seviyesi ölçer cihazı kullanılmıştır. Cihaz özellikleri: Fonksiyon İndeksi UA824, Ölçüm Aralığı: 30 130 dB, Doğruluk: 1,5 dB, Frekans Tepkisi: $31 \mathrm{~Hz} 5$ kHz ve Dinamik Arağı $50 \mathrm{~dB}$ dir. Atış ortamında sabitlenmiş silahın sağ tarafinda, $30 \mathrm{~cm}$ yanına yerleştirilmiştir.

Tablo 2'de yapılan iki farklı tür susturucu modeliyle yapılan atış gürültü ölçümleri görülmektedir. Gürültü azalma miktarlarını anlamak amacıyla, susturucu olmadan yapılan normal havalı silahla ilk atışlar yapılarak, referans değerler belirlenmiştir. İki farklı boyutta 3 hücreli olarak tasarlanmış prototip susturucularla ayrı ayrı 10'ar adet atış yapılarak ortalama ses ölçüm değerleri hesaplanmıştır. 
Tablo 2. Yapılan testler ve ölçüm değerleri

\begin{tabular}{|c|c|c|c|c|c|c|c|c|c|c|c|}
\hline \multirow{2}{*}{$\begin{array}{c}\text { EKiPMAN } \\
\text { (Modeller) }\end{array}$} & \multicolumn{7}{|c|}{ Atış Sayıları } & \\
\cline { 2 - 13 } & 1 & 2 & 3 & 4 & 5 & 6 & 7 & 8 & 9 & 10 & $\begin{array}{c}\text { Ortalama } \\
\text { (dB ) }\end{array}$ \\
\hline Susturucusuz & 86,9 & 81,2 & 78,6 & 79,4 & 85,7 & 83 & 78,2 & 87,7 & 85 & 89,1 & 83,5 \\
\hline $\begin{array}{c}\text { Susturucu 1 } \\
\varnothing \mathbf{2 0 x 7 2} \\
11 \text { gram }\end{array}$ & 75,1 & 76,2 & 72 & 69,6 & 74,3 & 77,9 & 71,8 & 73,4 & 75.6 & 72.2 & 73,8 \\
\hline $\begin{array}{c}\text { Susturucu 2 } \\
\varnothing \mathbf{3 4 x 9 4} \\
26 \text { gram }\end{array}$ & 72,4 & 68,4 & 66,8 & 70,3 & 71,1 & 68,4 & 69,3 & 67,5 & 71,7 & 68,8 & 69,5 \\
\hline
\end{tabular}

Sonuç

$\mathrm{Bu}$ çalışmada, havalı tabancalarda kullanılabilen tek parçalı, üç ara bölmeye sahip bir susturucu sisteminin tasarımı, 3B yazıcıyla prototip üretimi ve gerçek havalı silahla test atışları yapılmıştır. Havalı silahlarda namlu içinde ve namlu ağzı çıkışında yüksek 1S1 oluşmadığından, ABS malzemeden üretilen susturucular sorunsuz çalışabilmektedir. İnsan sağlığı açısından $80 \mathrm{~dB}$ ve üstlerinin olumsuz olarak bilindiği için geliştirilen iki model susturucuda, kapalı ortamda yapılan testlerde insan sağlığına az zararlı gürültü seviyesine indirgediği (80 dB değerinin altında) görülmektedir.

Havalı silah için susturucusuz normal atış ortalama ses şiddeti değeri 83,5 $\mathrm{dB}$ olarak ölçülmüştür. $\varnothing 20 \times 72 \mathrm{~mm}$ boyutlarında tasarlanmış susturucu 1 modeli prototip takıldıktan sonra yapılan atışlarda ortalamada 73,8 dB'e düşmüştür. $\varnothing 34 \times 94 \mathrm{~mm}$ boyutlarındaki susturucu 2 prototipi ise ortalamada $69,5 \mathrm{~dB}$ 'e kadar düştüğü görülmüş̧ür. Susturucu sistemlerde, namlu içerisinden çıkan basıncı absorbe edecek yeterli miktardaki hacim arttıkça daha iyi ses azalması sağlanmaktadır. Ateşli silahı kullanan kişilere, kullanım konforu sunmanın yanı sıra, yerinin tespit edilmemesi, çevreye rahatsızlık vermemesi gibi avantajlar sağlaması silahın tercih sebebi olmaktadır.

Havalı silah sistemleri için geliştirilen bir susturucu tasarım özelliklerinin anlatıldığı bu çalışmada, 3 ara ayırım duvarına sahip ve normal şartlarda tek parçalı 
imalatı mümkün olmayan susturucu modeli $3 \mathrm{~B}$ yazıcıda prototip olarak imal edilebilmiştir. Tek parça halinde imal edilebilme imkânı sağlayan 3B yazıcı teknolojisi sayesinde, ucuz, hızlı ve etkili havalı silah için susturucu imalatı yapılabilmiştir. Ateşli hafif silahlar sistemleri içinde aynı yöntem kullanılarak 3B metal yazıcılarla gerçekleştirilebilecektir.

\section{Extended Summary}

\section{Introduction}

Weapon, an instrument used in combat for the purpose of killing, injuring, or defeating an enemy Weapons may also be classified as conventional, destroying by kinetic energy or by chemical energy. Air gun, weapon based on the principle of the primitive blowgun that shoots bullets, pellets, or darts by expansion of compressed air. Most modern air guns are inexpensive BB guns. The best of these develop about half the muzzle velocity of light firearms, are accurate enough for marksmanship training at ranges up to $30 \mathrm{~m}$.

\section{Weapon Systems}

When powder is burned inside the chamber of a gun, and behind the bullet which is being forced down the barrel, it has a few micro seconds to build up pressure within the gun. As a result, when the bullet throws the barrel, there is a large pressure difference between the inside of the gun and the outside. So, one gets the "bang" as the the high pressure air decompresses into the atmosphere - just like a popping balloon, only more intense. A modern firearm works on the same principle as an air gun. High pressure air is released behind the projectile, and the easiest exit for that air is through the barrel of the gun.

\section{Suppressors}

A suppressor or sound moderator is a device that reduces the sound intensity and muzzle flash when a firearm or air gun is discharged. It can be a detachable accessory to, or integral part of, the muzzle or barrel. Suppressors are typically constructed of a metal cylinder with internal mechanisms to reduce the 
sound of firing by slowing the escaping propellant gas. Noise is an inherent characteristic of a gun and is usually associated with three main producers: the projectile, the muzzle, and the gun components other than the muzzle. The noises produced by the gun components are mostly mechanical such as the sounds of moving parts, impact, and vibration. The noises are mainly those caused by air turbulence following the projectile and the supersonic shock wave or ballistic crack generated by the projectile nose.

\section{D Printer}

In this study, computer aided design of the single particle suppressor for air guns. The design and fabrication processes that need to be applied during the manufacture of this masonry 3D printer are described. 3D printing or additive manufacturing is a process of making three dimensional solid objects from a digital file. The creation of a 3D printed object is achieved using additive processes. In an additive process an object is created by laying down successive layers of material until the object is created. Each of these layers can be seen as a thinly sliced horizontal cross-section of the object on the CAD system. 3D printing is the opposite of subtractive manufacturing which is cutting out / hollowing out a piece of metal or plastic with for instance a milling machine. 3D printing enables you to produce complex shapes using less material than traditional manufacturing methods. By examining the 3D printer printing parameters on suppressor for air guns, the suitability of 3D printers in suppressor manufacturing is examined.

\section{Conclusion}

The average sound intensity value for an air gun without a suppressor was measured as $83.5 \mathrm{~dB}$. The Suppressor 1, designed in $\varnothing 20 \times 72 \mathrm{~mm}$ (outside diameter and length) dimensions, dropped to $73.8 \mathrm{~dB}$ on average after the prototype was installed. The size of the $\varnothing 34 \times 94 \mathrm{~mm}$ "Suppressor 2" prototype dropped to $69.5 \mathrm{~dB}$ on average. In Suppressor systems, as the volume and the number of compartments are increased enough to absorb the pressure exiting the barrel, better sound reduction is achieved. In addition to providing user comfort, it also offers 
advantages to people who use firearms, such as not detecting the location, not disturbing the neighbour.

In this study, which describes a suppressor design features developed for air gun systems, a suppressor model design with 3 intermediate walls and no onepiece manufacture under normal conditions could be manufactured as a prototype in a $3 \mathrm{D}$ printer. $3 \mathrm{D}$ printer technology allows to be manufactured the objects in one piece. Suppressor production can be easily made such as cheap, fast and effective for air gun. It will be possible to use 3D metal printers in firearms with the same method for light weapon systems.

\section{Teşekkür}

$\mathrm{Bu}$ çalışma, Kırıkkale Üniversitesi Bilimsel Araştırma Projeleri Koordinasyon Birimince desteklenmiştir (Proje adı: Silah Mekanik Sistemleri İçin 3 Boyutlu Eğitim Modelleri Geliştirilmesi, Proje No: 2015/82).

\section{Kaynakça}

ÇOB (2011), Çevre ve Orman Bakanliğl, Çevresel Gürültü Ölçümü ve Değerlendirme Kılavuzu, Ankara.

Farrar C.L. and Leeming D. W., (1983), Military Ballistics: A Basic Manual, Brassey's Publishers.

Gezer H.A., (2017), Barut Tane Geometrisinin Silah İç Balistiğine Etkisinin Incelenmesi, Sakarya Üniversitesi, Fen Bilimleri Enstitüsü, YL Tezi, Sakarya.

Gündüzer O., (2011). Namlu Cidarı Boyutlandırmasına İç Balistik Davranışın Etkisi, Gazi Üniversitesi, Fen Bilimleri Enstitüsü, Yüksek Lisans Tezi, Ankara.

Menzies R.C., Scroggie RJ., Labowitz DJ., (1981), Characteristics of silenced firearms and their wounding effects, Journal of forensic sciences, 26(2), pp 239-262.

Seçgin E., Arslan H., (2012), Patlamalı Akışlarda Susturucunun Akustik İndirgemesi ve Performans Analizi, Savunma Teknolojileri Kongresi, ODTÜ. 
Warlow, T.A., (1996), Firearms the Law and Forensic Ballistics, London: Taylor \& Francis Publishing.

Yılmaz A., (2004), Ateşli Silahlarla Oluşan Yaralanmalar, Tbb Dergisi, Sayı 50, 167.

\section{Web siteleri}

3D printer, (2018), https://zortrax.com/ adresinden alınmıştır.

Air rifle, (2018), www.air-rifle.net/selecting/selecting.html adresinden alınmıştır.

Airguns, Accessories, (2018), http://www.beeman.com/BeemanCatalogs/2009\%20 Beeman \%20Catalog.pdf adresinden alınmıştır.

Ateşli Silahlar, (2017), https://tr.wikipedia.org/wiki/Ateşli_silahlar adresinden alınmıştır.

Cold (2018), https://tr.pinterest.com/pin/384213411953093431/ autologin=true, adresinden alınmıştır.

How works air rifles, (2018), http://blogs.howstuffworks.com/ how-pcp-air-rifleswork adresinden alınmıştır.

Technical information, (2018), http://www.makarov.com/tech.html adresinden alınmıştır.

Silencers, (2018), https://armsaholic.com/products/5ku-kac-qd-silencer-suppressor$14 \mathrm{~mm}$-ccw-for-tactical-airsoft-5ku-10 adresinden alınmıştır.

Straight Shooters Precision Airguns, (2018), http://www.straightshooters.com/ documents/generalpelletairguninfo.html adresinden alınmıştır. 